International Journal of Engineering \& Technology, $7(4.34)(2018)$ 177-179
International Journal of Engineering \& Technology
SPC
Website: www.sciencepubco.com/index.php/IJET
Research paper

\title{
Conceptual Design Approach of Hybrid UAV (Huav): Technology Enabler for Aerotourism in Malaysia
}

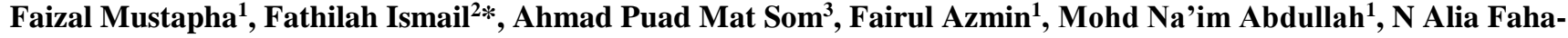 \\ da W Ab Rahman' \\ ${ }^{1}$ Faculty of Engineering, Universiti Putra Malaysia, 43400 Serdang, Selangor, Malaysia \\ ${ }^{2}$ School of Maritime Business \& Management, Universiti Malaysia Terengganu, 21300 Kuala Nerus, Terengganu, Malaysia \\ ${ }^{3}$ Faculty of Applied Social Sciences, Universiti Sultan Zainal Abidin, Gong Badak Campus, 21300 Kuala Nerus, Terengganu, \\ Malaysia \\ *Corresponding author E-mail: fathilah@umt.edu.my
}

\begin{abstract}
The introduction of Aerotourism using Unmanned Aerial Vehicle (UAV) is timely due to the importance of strong, positive destination image and how it works to influence tourist destination selection and satisfaction, as well as destination sustainability. UAV has certain advantages over piloted aircraft missions, which include the lower operating cost, improved safety, flexibility in mission planning, less expensive remote sensing platform, more rapid deployment capability than piloted aircraft and closer proximity to the target requirement. The increasing trend of UAV (fixed wing and rotorcraft) as part of image capturing and live telecasting has prompted many tourism operators to migrate into this autonomous technology. Unfortunately, due to its restricted design configurations and requirements related to fixed wing and rotorcraft UAV such as the need for landing strip and long endurance has receded the ultimatum usage of this technology. This paper aims to develop a conceptual framework of Aerotourism for destination image enhancement, as well as addresses the conceptual approach of Hybrid UAV (hUAV) by integrating fixed wing with rotorcraft. It is predicted that this enabling technology will achieve the smooth transition from hover to cruising and the realization of Aerotourism in Malaysia. This research could be considered as a breakthrough for Malaysian destination image, thus it could further boost the tourism industry in Malaysia.
\end{abstract}

Keywords: Conceptual framework; Unmanned Aerial Vehicle (UAV); Hybrid UAV (hUAV); Aerotourism.

\section{Introduction}

Unmanned aerial vehicle (UAV) also referred as unmanned aerial system or drone has become ubiquitous all over the world. It is suited for dull, dirty and dangerous tasks where pilot's safety is the utmost concern [1]. Development of UAV was once driven by military application such as surveillance and reconnaissance has gradually expanding for various applications such as survey and mapping, aerial imaging, search and rescue, remote sensing, recreational and many more forecasted number of sales for model aircraft (hobbyist) will double from 1.9 million in 2016 to 4.3 million in 2020 while for non-model aircraft (commercial) will increases fourfold from 0.6 million to 4.7 million for the same period [2]. The global UAV market for non-military is estimated worth USD2.6 billion in 2016 and will rise to USD10.9 billion in 2025 [3]. Currently, non-military market is dominated by Dajiang Innovation Technology (DJI) based in Shenzen, China with estimated market share of $70 \%$ [4].

UAV can be flown autonomously by pre-programmed flight path or controlled actively by pilot via controller. In autonomous flight, pilot may take control of the flight at any time by disabling the autopilot and must ensure visual line-of-sight (VLOS) contact with UAV [5-6].

\subsection{Comparison of Fixed Wing and Rotorcraft}

Basic fixed wing UAV construction composed of airfoil shaped rigid wing to generate lift caused by the forward airspeed. UAV is controlled by ailerons (perform roll), elevator (perform pitch) and rudder (perform yaw). On the other hand, rotorcraft construction is more complex than fixed wing. It generates lift from two or more airfoil shaped blades revolving around the fixed mast. This setup is called rotor. Single rotor can be seen on helicopter with one more rotor positioned at tail to control heading. Multirotor or multicopter instead has more than two rotors and nowadays tricopter (three rotor), quadcopter (four rotor), hexacopter (six rotor) and octacopter (eight rotor) are becoming common.

Both fixed wing and rotorcraft has its own advantages and disadvantages. Fixed wing structure is more aerodynamic and hence able to attain high cruising speed, better endurance and covers more footprint compared to rotorcraft [7]. Fixed wing also has the capability to glide even without power once it has obtained minimum forward thrust. However, fixed wing require runway to take off and land. Unlike fixed wing, rotorcraft does not need a runway, allowing it to fly in a confined space and in a very congested and fragile area. Moreover, rotorcraft able to hover in a fixed position allowing it to maintain visibility on a target. 


\subsection{Platform Configuration}

To date, there are a lot of configurations for hybrid UAV. Most notable types are tilt rotor, tail sitter and standard plane. All these types are capable to perform VTOL.

Tilt rotor generate lift from multiple rotors mounted on rotating shafts. To execute forward flight, the rotors gradually rotated parallel to flight direction for cruising. During cruising, rotors produce forward thrust and the wing provide the lift from the airstream. Example is shown below.

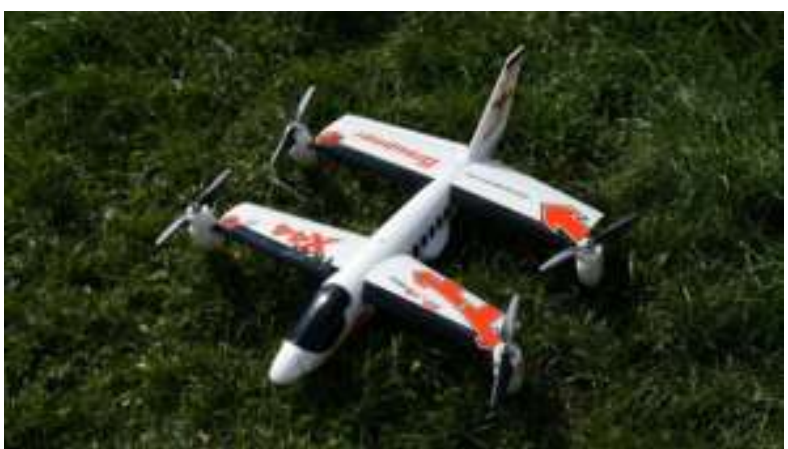

Fig. 1: Graupner X44 [2]

Tail sitter type of UAV sits and landing vertically on its tail and the whole body rotates horizontally for forward flight. Such configuration is as illustrated below.

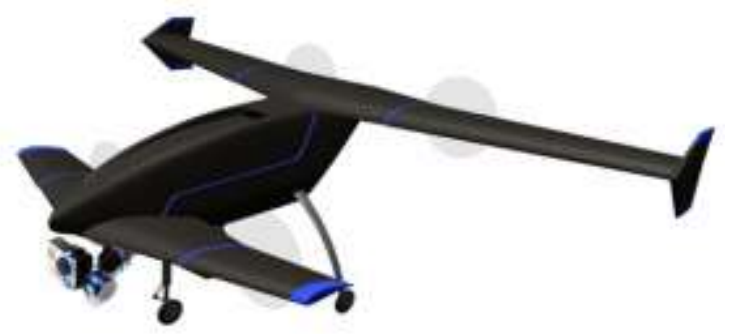

Fig. 2: Vertex Hybrid [3]

Standard plane UAV looks just like conventional airplane as depicted in Figure 3. It has wing to generate lift, fuselage to houses electronic components and tail for stabilizer. Control surfaces (aileron, elevator and rudder) are attached to airframe for attitude control.

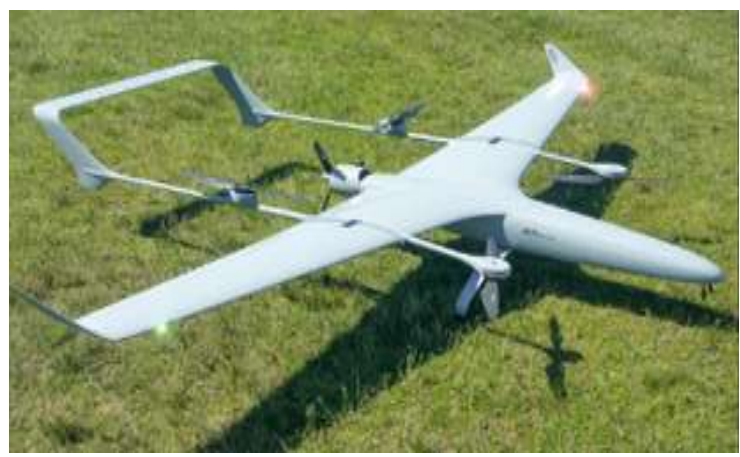

Fig. 3: Example of standard plane [3]

\subsection{Research Motivation}

Fixed wing lacks the ability to hover and require substantial length of runway for takeoff. Rotorcraft on the other hand has low cruising speed and hence can only covers limited range per flight. This paper addresses the synergy of these two configurations by integrating fixed wing with rotorcraft. In addition, smooth transition from hover to cruising and vice versa has be maintained, so that hUAV will not crash during flight.

\subsection{Setting the design mission requirements and specifi- cations of hUAV}

Design requirements for this proposed Aerotourism project are given in the table below.

\begin{tabular}{|c|c|} 
Table 1: Design requirements \\
\hline Parameter & Requirement \\
\hline Size class & $\begin{array}{c}\text { Small UAV } \\
(0.05-2 \mathrm{~m})\end{array}$ \\
\hline Range and endurance & $\begin{array}{c}\text { Very Low Cost Close Range } \\
<5 \mathrm{~km} \text { and }<\$ 10,000\end{array}$ \\
\hline VTOL & yes \\
\hline Weight & $<3 \mathrm{~kg}$ \\
\hline
\end{tabular}

\section{Methodology}

Design methodology begins with identifying requirements. It is then followed by configuration design where design possibilities are explored by manipulating the airframe design, rotor configuration, body dimensions, and number, size and location of rotors. Moreover, predetermined components are selected to make an assembly of components together with the interfacing between components is sought that satisfies a set of requirements and obeys a set of constraints [8].

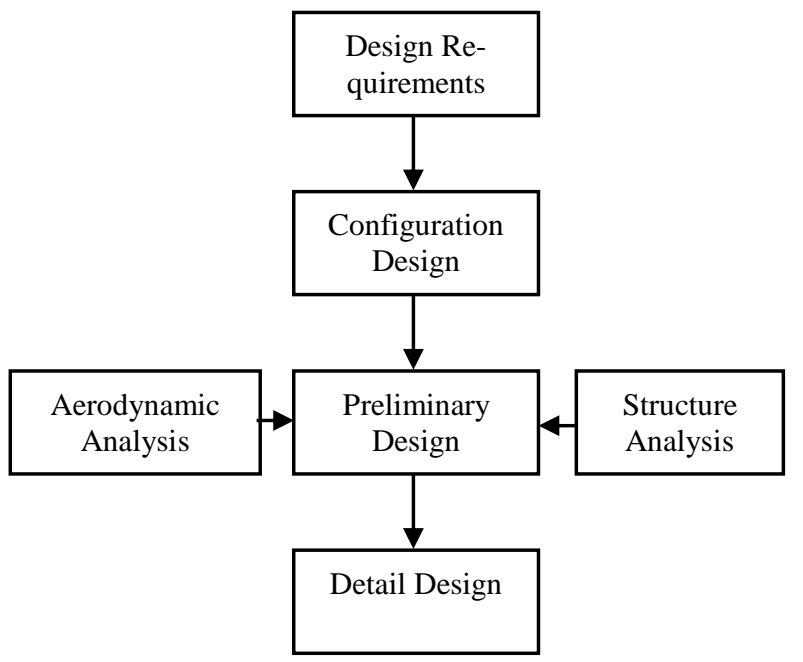

Fig. 4: Design Process

\section{Idea and Concept Generation}

From the literature review together with the budget constraint, the standard plane configuration seems a way to go. The objective of the design in this concept generation is to have a unique and sound design and no one has attempted before. Figure 5, highlight all the concept that possibly meet the final design mission requirement for hUAV for Aerotourism purposes.

The aim for the first attempt is to produce hybrid UAV at very low cost. The fuselage design is shaped as a cylinder and house almost all the electronic components. A tractor propeller is placed at the nose of the fuselage to provide the main forward thrust. Conventional tail configuration is selected in in the view of its simplicity. Four tractor motors sit on rod for VTOL operation.

The second concept almost similar to the first concept but this time around the four tractor motors sit on landing struts used in helicopter. This design provide room to place camera gimbal or other protuberance under the fuselage.

The third concept slightly differs than the previous concepts. Rotors for VTOL are combination of tractor and pusher rotor. Two pusher rotors are place on a rod where it cross through the fuselage. Two tractor rotors sit on boom mounted tail. 
The forth concept make use of the widely available quadcopter airframe in the market. The fuselage no longer aerodynamically shaped and the wing is places between the upper and lower frame. The fifth concept transforms commercial off the shelf (COTS) remote control (RC) aircraft frame into hybrid UAV. A few aircraft frame can be considered for example Light Aircraft 182, Hornet Hi-Wing Trainer, Volantex Ranger EX and many more. What need to be added to make it hybrid UAV are four rotors mounted on the wing. Since many of RC aircraft are made of EPO for its lightweight, the wing need to be reinforced with tube to support weight of quadrotor.

The last concept is the opposite of the fifth concept. Transforming quadrotor into hybrid UAV approach is more practical with the quadrotor has become ubiquitous nowadays. The design is derived from the imitation of flying squirrel. The flying squirrel cannot actually fly but they can glide by extending a fold of skin that stretches from their wrists to their ankles $[9,10]$.

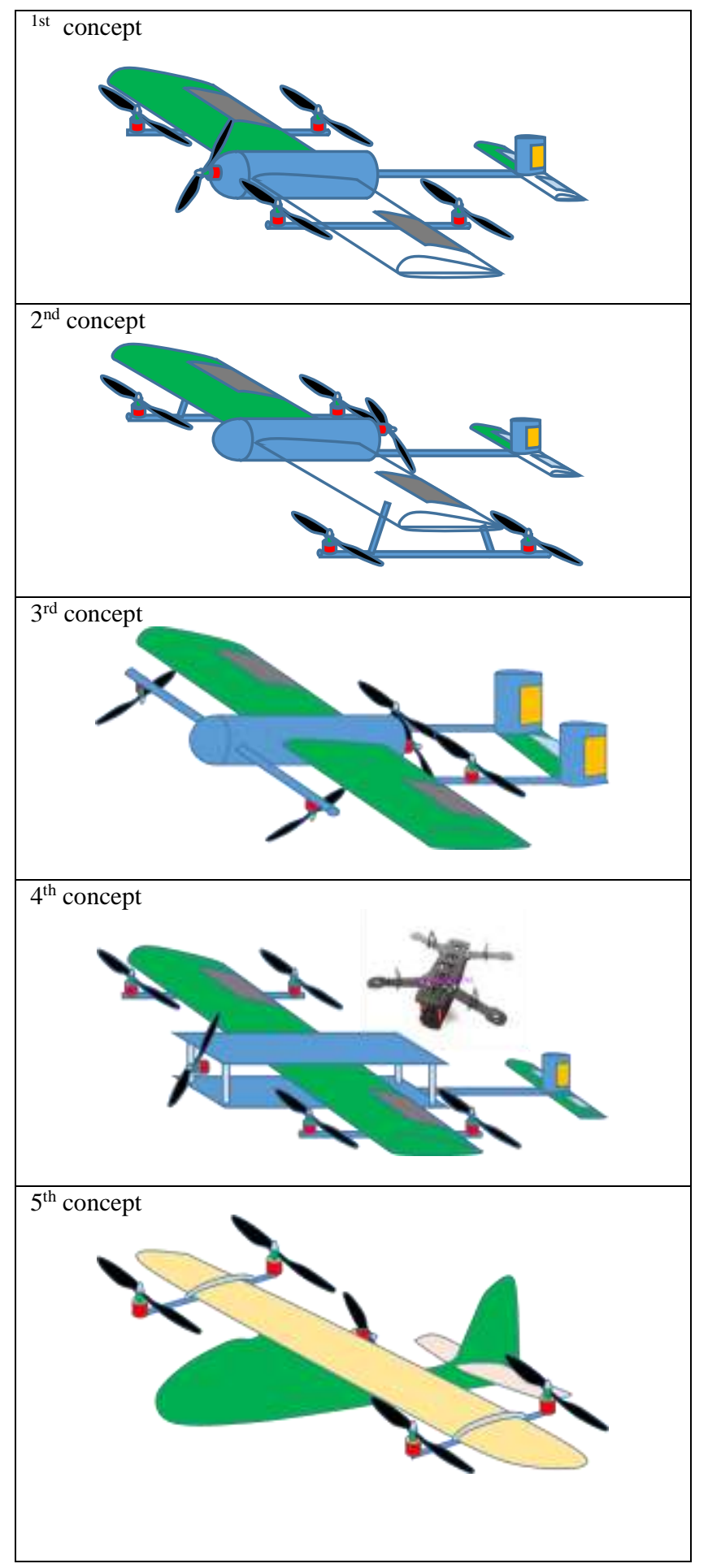

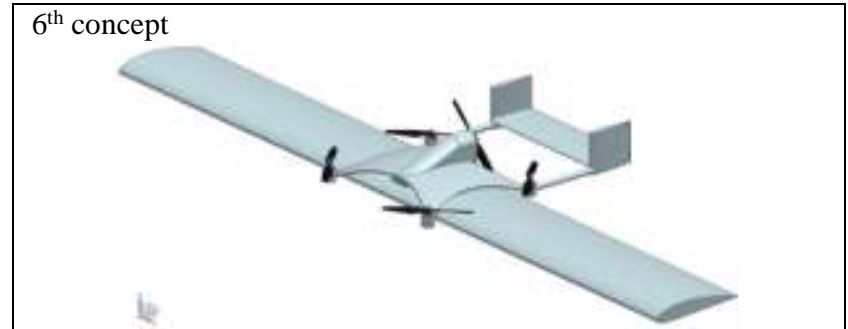

Fig. 5: Few of the Conceptual Design of Hybrid UAV

\section{Conclusion}

The best concept for the hUAV for Aerotourism mission profile can be considered the $6^{\text {th }}$ design; as from the design perspective and flight performance this proposed concept can be said feasible and the setting mission requirements profile can be strategically achieved. Besides, the advantage of using similar to "flying squirrel" shaped airframe is the capability to glide even without wing mounted on the airframe. In this concept, the wing and tail are being detachable, so the ground pilot can have the options not only to use quadcopter configuration alone or turn it into a hybrid UAV for tourism purposes.

\section{Acknowledgement}

The authors would like to thank the Research Management, Innovation and Commercialization Centre, Universiti Sultan Zainal Abidin, Terengganu, Malaysia for providing the financial assistance to support the publication fee of this article.

\section{References}

[1] International Civil Aviation Organization (ICAO). 2011. Unmanned Aircraft Systems (UAS). ICAO.

[2] Federal Aviation Administration (FAA). 2016. FAA Aerospace Forecast Fiscal Years 20169-2036. FAA.

[3] Teal Group. 2016. Teal Group predicts worldwide civil UAS production will total $\$ 65$ billion in its 2016 UAS market profile and forecast. http://www.tealgroup.com/index.php/about-teal-groupcorporation/press-releases/129-teal-group-predicts-worldwide-civiluas-production-will-total-65-billion-in-its-2016-uas-market-profileand-forecast.

[4] Sean. P. 2015. Drones: A rising market. http://sophiccapital.com/wp-content/uploads/2015/09/DownloadSophic-Capitals-Aerial-Drone-Report-Here.pdf.

[5] Oppenheimer and Co. Inc. 2016. Drone industry report. http://pdf.zacks.com/pdf/FA/H4947044.PDF.

[6] Ben, C. 2015. Vertex hybrid drone combines hovering and fixedwing flight. http://newatlas.com/vertex-hybrid-drone/37159/.

[7] Regardt, V. D. B. 2016. Meet transition, the SA-made fixed-wing drone. https://www.techcentral.co.za/meet-transition-the-sa-madefixed-wing-drone/66048/.

[8] Wielinga, B. J., \& Schreiber, A. T. H. 1997. Configuration design problem solving. http://www.cs.vu.nl/ guus/papers/Wielinga97a.pdf.

[9] U.S. Fish and Wildlife Service. 2011. Carolina northern flying squirrel. https://www.fws.gov/asheville/pdfs/ CarolinaNorthernFlyingSquirrel_factsheet.pdf.

[10] John, B. 2015. Building your own drones: A beginners' guide to drones. UAVs, and ROVs: Que Publishing. 